\title{
Earth Remote Sensing in NWS Severe Weather Damage Assessments
}

\author{
Adapted From "Incorporation \\ and Use of Earth Remote Sensing \\ Imagery within the NOAA/NWS \\ Damage Assessment Toolkit," by \\ A. Molthan (NASA Marshall Space \\ Flight Center), L. A. Schultz, \\ K. M. McGrath, J. E. Burks, J.P. \\ Camp, K. Angle, J. R. Bell, and G. J. \\ Jedlovec. Published online in BAMS, \\ March 2020. For the full, citable \\ article, see: DOI:10.1175 \\ /BAMS-D-19-0097.1.
}

$\Lambda$ fter an observed or suspected tornado, meteorologists in NOAA's National Weather Service (NWS) typically perform a detailed damage assessment in collaboration with emergency managers, affected citizens, insurance providers, and others. Damage assessment includes collecting event observations, making site visits, ensuring rigorous data entry, and conducting quality control to synthesize into the official NOAA/NWS Storm Data record. Assessments are as rapid as possible to document damage indicators prior to cleanup and inform users who map impact and recovery needs, including local and state emergency managers, the Federal Emergency Management Agency (FEMA), insurance companies, and local governments.

Use of laptops, GIS software, and handheld GPS and Blackberry devices to expedite collection and mapping for damage assessment led to the current NOAA/NWS Damage Assessment Toolkit (DAT). Using the DAT, NWS meteorologists and others collect damage information through geotagged photos and in-app questionnaires that tie observations to appropriate Enhanced Fujita (EF) scale damage indicators. The DAT-supported collaboration in the field corroborates information with 
complementary datasets. For example, the DAT can incorporate Civil Air Patrol (CAP) photography and radar observations to place damage within a meteorological context. With the DAT, field assessment teams, WFOs, and their Regional Operations Center together ensure quality control and consistency before analyses are shared with the general public.

The DAT has also enabled opportunities to improve damage assessment using newly available satellite information. Among the effects of severe weather-including not just tornadoes but also damaging winds, hail, and their combination-are changes in land surface vegetation and urban settings that are frequently observable using satellite remote sensing. The spatial resolution needed to observe these changes is improving, and this growing volume of satellite remote-sensing data and information is motivating exploratory efforts to increase and consolidate the information available to support damage assessment. The NASA Applied Sciences Disasters Program awarded a feasibility study to integrate Earth remote-sensing information in the DAT. In the study, NWS WFOs in the central and southern region provided feedback on the benefits of including remote-sensing imagery within the DAT client. We will discuss two cases from the study in which use of the DAT with land-surface information based on satellite imagery improved complex damage assessments .

\section{Remote sensing for damage assessment}

Several previous studies have looked for changes in land-surface remote sensing data to identify damage from winds, hail, and tornadoes. Satellite remote sensing and aerial imagery have also been used with radar data to help locate tornadogenesis and diagnose relationships to convective structure. In early studies, satellite imagery from Terra, Aqua, and Landsat-7 Enhanced Thematic Mapper Plus (ETM+) and other data from onboard instruments were used to identify damaged areas from tornado and midwestern hail events. Visual examination of a single-day Normalized Difference Vegetation Index (NDVI), which shows damaged vegetation with satellite data, was used to identify tornado tracks across Alabama following the 27 April 2011

tornado outbreak. Further research expanded upon previous use of postevent ASTER (higher-resolution) and MODIS (lower-resolution) satellite imagery with Alabama NWS partners immediately after the outbreak.

While satellite imagery has demonstrated application to mapping broad damage paths, higher-resolution satellite and aerial imagery (from low-altitude flights, drones, and/or specialized commercial imaging) can provide

Among the effects

of severe weather are changes in land surface vegetation and urban settings that are frequently observable using satellite remote sensing. more detailed structural damage assessment. The DAT study discussed here involved evaluation of the effectiveness of remote sensing imagery from a variety of platforms. NASA's Terra and Aqua MODIS and the NASA/NOAA Suomi NPP VIIRS imagery were used to generate daily NDVI and true color composites. True color, false color, NDVI, and higher-spatial-resolution panchromatic imagery from Landsat-7 ETM+ were made available in early phases of the project (and then replaced by Landsat-8 Operational Lab Imager imaging). Repeat coverage was provided every 16 days. For major events, USGS and NASA collaborate with JPL for tasking of Terra/ASTER to contribute 15-m NDVI and false color composites for damage swaths targeted within view of the Terra ground track.

These sources were complemented by eventspecific requests to the USGS Hazards Data Distribution System (HDDS), including collections from the French commercial Système Pour l'Observation de la Terre (SPOT; translated System for Observation of Earth) series. SPOT provides visible and infrared bands comparable to Terra ASTER and Landsat-7/8, over a smaller coverage area but at higher spatial resolution than Landsat.

USGS HDDS frequently acquires DigitalGlobe Worldview-1, Worldview-2, and Worldview-3 visible and near-infrared imagery (1-5 m) and a separate panchromatic band (0.3-0.46 m, sensor specific). Beginning in 2018, USGS HDDS also provided a pan-sharpened version that combines the best of the visible, near-infrared, and panchromatic into a single image (Worldview-3 only). Planet Laboratories has recently begun contributing imagery for major disasters and may be an additional resource in the future.

Other imaging assets are occasionally provided through activation of the International Charter on Space and Major Disasters (https:// disasterscharter.org). For example, Pléiades imagery from Airbus has contributed 0.5-m 
imaging following tornado outbreaks. These imagery often require additional days to collect cloud-free views. Meanwhile, many private companies offer satellite imagery to the general public through their web pages and other outlets.

\section{Case study: 10 May 2015 outbreak}

In one case, the damage assessment of interest focuses on an EF-1 tornado that tracked near Lidderdale, Lake City, and Rockwell City among very large hail, damaging winds, and other tornadoes in west central Iowa, on the evening of 10 May 2015. Staff in the Des Moines, Iowa, forecast office examined Worldview and SPOT imagery in both true color and grayscale panchromatic. Use of these images led the forecast office staff to make a key correction in the overall length and direction of the tornado track, and to discriminate between areas

\section{SPRT II NOAA/NWS DAT: Satellite Imagery Quick Guide Landsat 8: Natural Color}

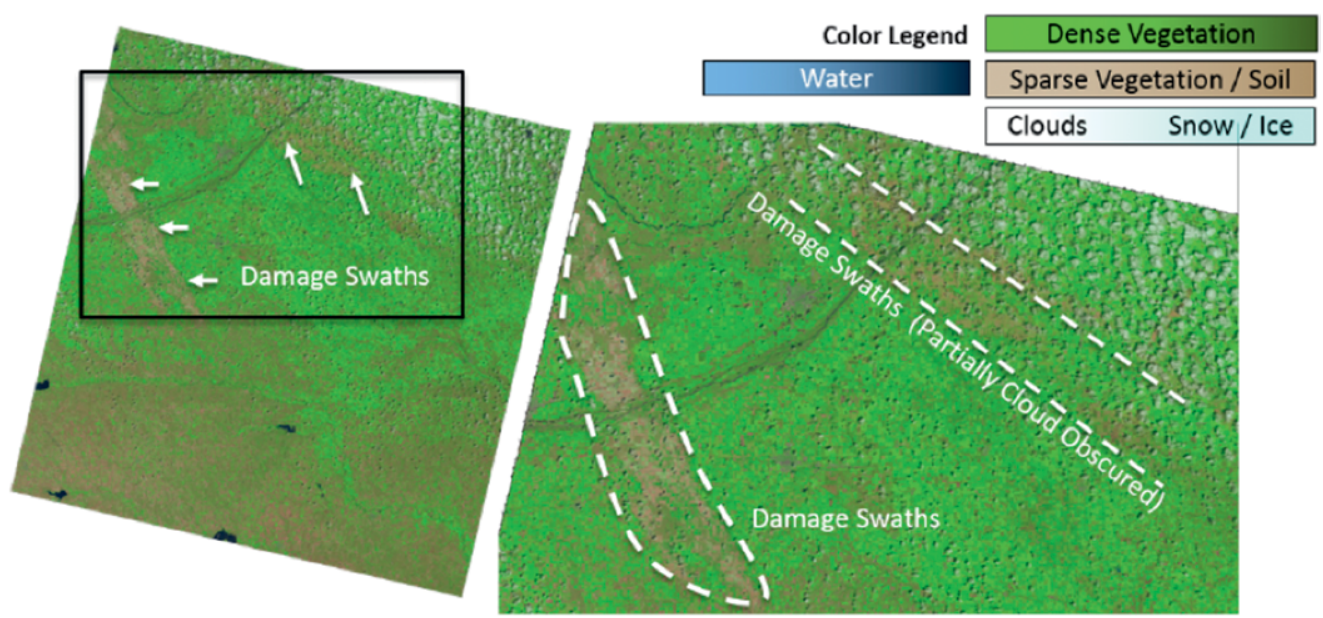

15 July 2014, Landsat 8 Natural Color in Central Nebraska

\begin{tabular}{|r|l|}
\hline Access & $\begin{array}{l}\text { SPoRT > Landsat 8 } \\
\text { Natural Color }\end{array}$ \\
\hline Restrictions & None \\
\hline Resolution & $30 \mathrm{~m}$ \\
Latency & $\begin{array}{l}\text { Landsat } 8 \text { has a 16 day repeat } \\
\text { cycle. It observes the same } \\
\text { location every 16 days. }\end{array}$ \\
Spectral \\
Bands & $\begin{array}{l}\text { USGS / NASA SPoRT } \\
\text { Three red and near-infrared } \\
\text { bands (6,5,4) are combined to } \\
\text { create an image similar to true } \\
\text { color, but with additional } \\
\text { discrimination of clouds and } \\
\text { snow. } \\
\text { Application }\end{array}$ \\
$\begin{array}{l}\text { Damage tracks are typically } \\
\text { identified as brown scars } \\
\text { against a green, vegetated } \\
\text { background. Corroborate } \\
\text { suspected damage tracks with } \\
\text { other information. }\end{array}$ \\
\hline
\end{tabular}

How is the image generated?

- Reflectance in the red and near-infrared bands $(6,5,4)$ is combined into a single false-color image to approximate a true color appearance.

What should I be looking for in this product?

- Red and near-infrared bands are often used to measure vegetation health. Tracks are apparent as linear features along the storm path, typically in shades of brown where vegetation and soils have been disrupted.

- Suspected track location can be corroborated with radar rotational track information or survey information.

What are the product limitations?

- Limited swath width may truncate portions of the track that continue outside of the scene.

- Clouds and cloud shadows may obscure portions of the damage track.

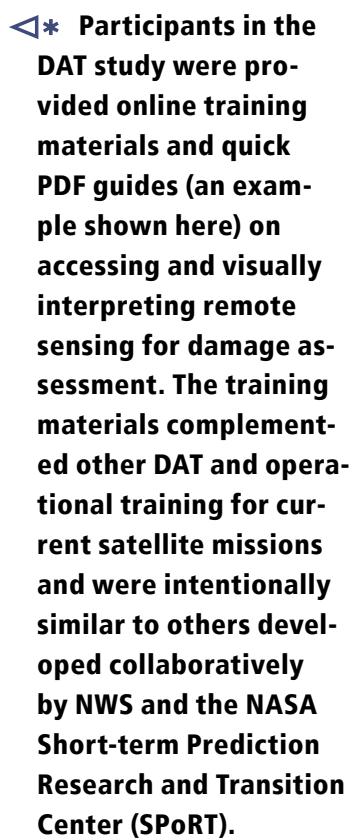


of tornado damage and those likely caused by strong, straight-line winds associated with the associated supercell's rear-flank downdraft. Landsat-8 OLI complemented the ETM+ collection with observations on 17 May.

Prior to examining the imagery, damage assessors had developed a preliminary track to include damage indicators that began near Lidderdale and extended northeastward toward Lake City. Assessors noted that damage indicators near Lidderdale may not have been associated with the tornado damage path, and that additional investi- gation with radar would be required. When SPOT imagery became available on 12 May, the panchromatic imagery captured distinct swirl textures associated with scouring of an open field by the tornadic circulation-but to the north and west of the original damage assessment track. In combination with radar data, the imagery guided the extension of the assessment polygon and track line southwest of Lake City into rural areas, including those where field scarring was evident in SPOT imagery. As a result, the damage assessment team adjusted the tornado damage path to
Damage assessment $* \square$ polygons prior to (purple, hatched) and following (yellow and red, filled) the inclusion of 12 May 2015 SPOT imagery for analysis. Inset area is representative of field scarring from the tornado seen elsewhere in the SPOT image. The red shaded region and thunderstorm damaging wind indicators represent the area reassessed and classified following SPOT imagery analysis. Source imagery copyright 2015 through the NextView license. $94^{\circ} 50^{\prime} 0^{\prime \prime} \mathrm{W}$

$94^{\circ} 45^{\prime} 0^{\prime \prime} \mathrm{W}$ $94^{\circ} 40^{\prime} 0^{\prime \prime} \mathrm{W}$

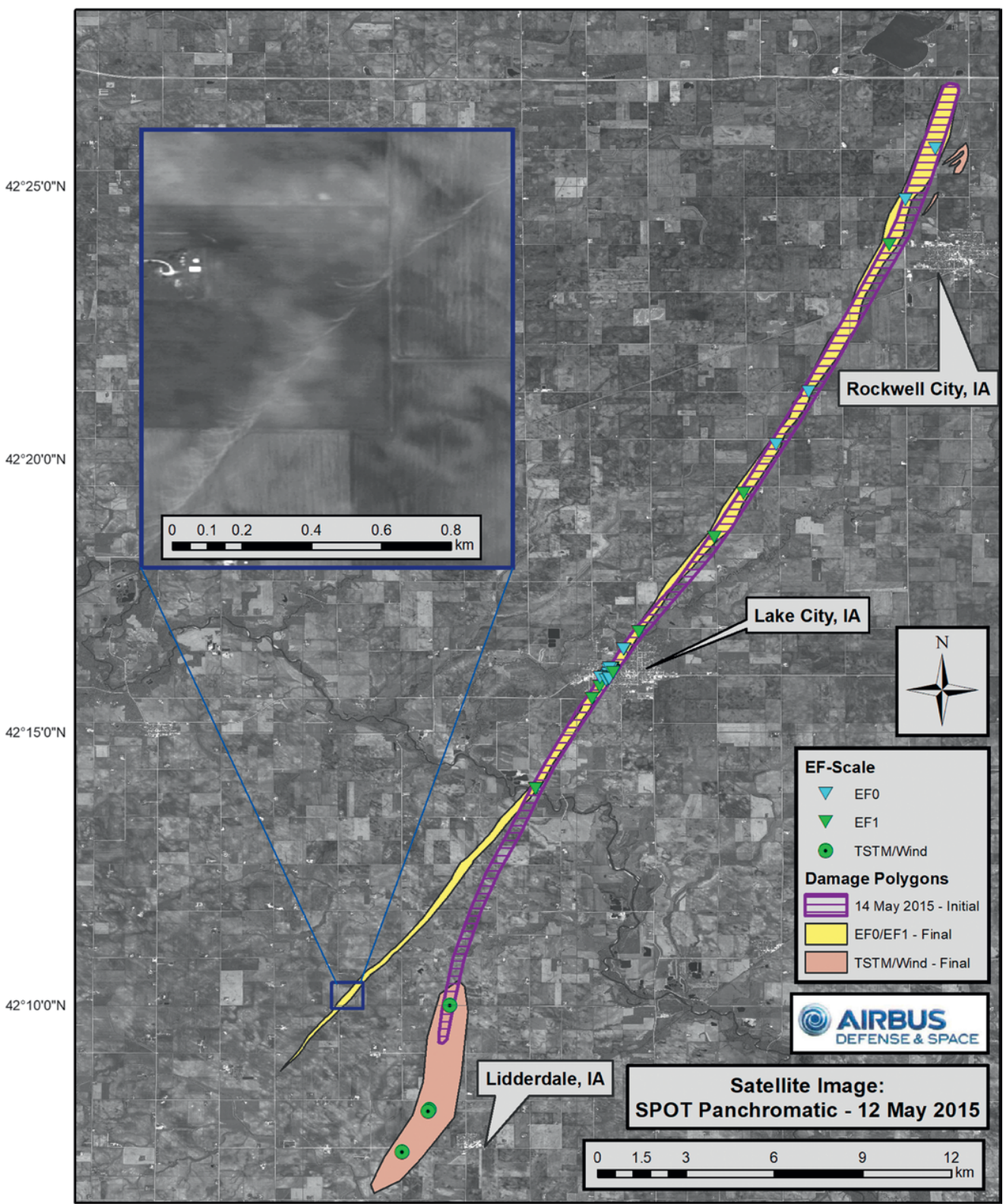


shift $4 \mathrm{~km}$ westward, adding about $1 \mathrm{~km}$ of length to the entire track, then separated this tornado track from damage indicators in the Lidderdale area that were instead attributed to damaging winds associated with the tornado-producing supercell.

SPOT imagery helped documentation of another brief tornado southwest of Manson, Iowa, which had also been reported by a severe weather spotter. Meteorologist Kevin Skow (then of WFO Des Moines) noted that the "modifications you are seeing in the DAT are a direct result of what we found in the satellite data. A second storm produced wind damage within a few miles of the actual tornado path that same night. The damage assessment team thought that this damage might be from the tornado. However, the satellite data showed that the path was farther to the northwest. The satellite data also helped us fine tune the path north of Lake City. The satellite data have proven once again to be a great asset for our storm surveying operations."

Farther north and west, staff at WFO Sioux Falls, South Dakota, were able to adjust a damage track based upon observations of field scour revealed by SPOT-6 imagery, which is particularly helpful in confirming tracks in remote rural areas. The greater levels of detail in higher-resolution commercial imagery helped when adjusting small-scale details of damage tracks, while coarser-resolution imagery still proved helpful in cases with longtrack events leaving significant and long-term change.

\section{Case study: 22 June 2015 outbreak}

Our second case features numerous wind and tornado damage reports in a 22 June 2015 tornado outbreak in Iowa, southern Wisconsin, northern Illinois, and Michigan, with additional damaging wind reports farther east. The WFO in Des Moines requested supplemental imagery through the USGS Hazards Data Distribution System to support damage assessments for tornadoes reported in the southern portion of their county warning area, near Columbia and Albia, and further east near Eddyville, Iowa.

Worldview-2 provided a first glimpse for the staff in Des Moines after acquiring imagery on 3 July, including multispectral and panchromatic views that included the entire length of the previously assessed damage indicators for the tornado of interest. In this case, satellite imagery helped to evaluate and quality-control the original damage assessment and investigate less-populated areas where access was restricted. The imagery was used to separate the original, single track into two distinct tornado events.

NWS meteorologist Kevin Skow stated that "as usual, the satellite data proved of great help...(and indicated) a break in the Columbia track, which we were unable to confirm on the ground assessment due to the poor road network and thus had originally kept it as one track. The satellite data also show some interesting characteristics of the tornado, including a pivot point just prior to the tornado's intensification to EF-3, and concentrated areas of damage in valleys where there is an enhanced inflow into the tornado. Due to the trees/grassland nature of the area, the true color imagery was more useful...since the resolution was not quite high enough to discern downed trees but could pick out the color differences between the live and dead vegetation (basically, a rudimentary version of an NDVI comparison)."

The original assessment included an approximately $30-\mathrm{km}(18.6-\mathrm{mi})$ single tornado track from south of Columbia to Albia. A second track was just to the east and south of Eddyville. Imagery from DigitalGlobe was used within the web-based DAT interface to further evaluate damage and revise the track. In this case, imagery provided spatial detail that was helpful for separating the original long-track tornado into separate tracks of varying impacts and maximum intensity.

The WFO in Grand Rapids, Michigan, also requested imagery supporting a damage assessment near Portland, Michigan. Imagery provided to the WFO was used to compare with available CAP photography. Users commented that the satellite perspective would be valuable for other events where CAP imagery was not widely available.

\section{Future work}

The two case studies presented here clearly show the value of imagery and other remotely sensed data in establishing and refining storm damage tracks, and identifying the source of those tracks (e.g., tornado, straight-line winds, hail), particularly in remote and difficult-to-access areas. 
Combinations of remote sensing and damage information may also benefit analysis of impacts from other hazards (including hurricanes) given available algorithms for mapping flood from polar-orbiting and geostationary satellites, burn scars, and other damaging phenomena. Remote sensing may also encourage more routine mapping of hail damage during the peak of the growing season. Hail damage is frequently observed from geostationary and polar-orbiting satellite imagery.

The ever-expanding constellation of Earth remote-sensing platforms from NASA, NOAA, international, and commercial sources continues to provide new capabilities with a growing number of spectral bands, higher spatial resolution, and reduced data latency. While clouds have proven challenging to the use of visible, near-infrared, and thermal remote sensing, free and open synthetic aperture radar (SAR) data has demonstrated potential for the identification of tornado tracks and hail damage. SAR is advantageous because of its sensitivity to vegetation structure, nighttime imaging, and many platforms operating at wavelengths penetrating all but the heaviest of rain or snowfall rates.

These new capabilities underscore the need for and value of the DAT. The NOAA/ NWS DAT can incorporate newly developed objective measures of storm-specific change detection. For example, approaches incorporating a more rigorous disturbance index could automate some detections as a complement to visual interpretation or true color imagery or NDVI. Automated change detection methods may prove most beneficial for lower-resolution sensors: algorithms detecting change at lower spatial resolutions may draw out details missed by subjective evaluation.

We hope that these advancements and continued inclusion of imagery will motivate new automated techniques and broader use of imagery within the damage assessment process with potential to support emergency managers through mapping of additional disaster impacts $\bullet$

\section{METADATA}

BAMS: What would you like readers to learn from this article?

Andrew Molthan: There will continue to be new and innovative ways to apply satellite data to disaster scenarios. The U.S. seems uniquely well suited for this with a lot of expertise in ground damage surveys. We are learning where satellite imagery can and cannot allow damage estimates to be made more quickly where detailed ground surveys are limited. Much of this effort is also being complemented by drone photography and even new 3D imaging from low-altitude aircraft.

BAMS: What surprises you the most about the work you document in this article?

AM: There is a large volume of remote sensing data from a diverse set of platforms, especially with growing commercial offerings and a lot of federal agencies partnering in the acquisition and sharing of the data. It was great to meet many collaborators as part of our learning process, and exciting to see these capabilities continuing to grow.

BAMS: What was the biggest challenge you encountered while doing this work?

AM: Many of the challenges come down to the complexities of the data. You want to find the highest-resolution, cloud-free data available and provide it in a way helpful for an analyst to use. The diversity of data providers, formats, and capabilities requires a lot of effort to synthesize information and bring it all together.

BAMS: How will you meet this challenge?

AM: A lot of folks in the community are working on automated algorithms that will advance this further. We have several projects at NASA Marshall Space Flight Center focused on working to help end users make use of remote sensing data. 